\title{
Key Indicators and Dimensional Causes of Accident on Construction Sites
}

\author{
Irewolede Aina Ijaola \\ Yaba College of Technology, Yaba, Lagos, Nigeria \\ Kudirat Ibilola Zakariyyah \\ University of Lagos, Lagos, Nigeria \\ Adebimpe Omorinsola Akerele and Olatunbosun Hezekiah Omolayo \\ Yaba College of Technology, Yaba, Lagos, Nigeria
}

\begin{abstract}
Diverse causes of accidents abound on construction sites, which lead to complexity and difficulty in understanding the key causes of accidents on construction sites. The effect is the increasing rate of accidents. Thus, grouping and identifying the key dimensional and sub causes of accidents is important. However, there is a dearth of research on the dimensionality and indicators of causal factors of accidents on construction sites. This paper aims to create an avenue for easy identification and understanding of the causes of accidents through the development of key indicators and dimensional causes of accidents on construction sites. Adopting a cross-sectional survey research design, three hundred questionnaires were purposely distributed to construction workers who have had experience or witness accidents on a construction sites. Two hundred questionnaires were retrieved and used for analysis representing a 67\% response rate. An exploratory factor analysis was used to group and find the significant causal factors from the 64 factors identified in the literature. From the analysis, five key dimensional causes with 22 indicators were identified namely; personal and work factors, design factors, behavioural factors, proximate factors and attitudinal factors. The key indicators identified among others are non-use of PPE, lack of experience, working in confined spaces, disobedience to work discipline and innovative technology. To reduce the occurrence level of accidents, site managers should place the key indicators and dimensional causal factors of accidents on the signboard for easy identification and understanding and as a training guide on construction sites.
\end{abstract}

\section{Article History}

Received : 31 May 2020

Received in revised form : 05 October 2020

Accepted : 07 December 2020

Published Online : 31 December 2020

Keywords:

Accident, Construction site, key dimensional, key indicators

Corresponding Author Contact:

irewolede.ijaola@yabatech.edu.ng

DOI: $10.11113 /$ ijbes. v8.n1.614

\section{Introduction}

The construction industry has earned the reputation of the most hazardous industry with the highest accident rate. This is due to the frequent occurrence rate of accidents on construction sites. The construction industry in Nigeria is not exempted from this malice although there is no readily available national record of accidents. Despite this, Eze et al. (nd) investigated the severity rate of accidents on Nigerian construction sites for over five years.
733 cases of mild accidents and 55 cases of fatal injuries or death were reported. Adekunle et al. (2018) investigated the causality rate of accidents in the Nigerian construction industry and found out that the fatality rate of accidents in the year 2015 is $90.8 \%$, with $15 \%$ wounded people, $19.5 \%$ lost their lives and $34.9 \%$ were amputated. Statistics from the year 2001-2015 show that there were 4,777 fatalities in the construction industry. $68 \%$ of these fatalities occurred in non-residential construction and specialty trade, 3\% occurred in other construction and specialty 
trades and 29\% occurred among construction workers in the home building industry (Adekunle, et al., 2018). The severity of the accident rate shows that there is a great need to prevent the occurrence of accidents on construction sites. The prevention of accidents starts with a clear understanding of the factors that play a significant role in causation (Al- Tabtabal, 2002). According to Dodoo and Al-Samarraie (2019), if accidents are to be reduced in the workplace, there is a need to place more emphasis on the genesis of accidents. Previous studies (Kadri et al., 2014; González et al. 2016; Williams et al., 2018), identified the various causes of accidents on construction sites but Dodo and AlSamarraie (2019) noted that the previous studies models have been criticised for not having key indicators that show the causes of incidents in the workplace. For example, Promscorn et al. (2015) worked on the root causes of construction accidents from the perspective of non-human factors. The study only identified the root causes of accidents from the perspective of non-human factors but neglected the other factors like the human factor. Furthermore, the study failed to identify the key indicators of the causes of accidents on construction sites. Williams et al. (2018) grouped the causal factors of accidents according to project participants; the client, the consultants, and the contractors but failed to identify the key indicators that show the causes of accidents on construction sites. Umar and Egbu (2018) investigated the root causes of accidents on road construction projects and concluded that the major causes of accidents can be grouped into equipment/materials, workers, environment and management. However, the key indicators of the grouped causes were not investigated. There seems to be dearth of research on the key indicators and dimensional causes of accidents on construction sites. Thus, the study aims to develop the key causes of accidents on construction sites in Nigeria with the view to creating an avenue for easy identification and understanding of the causes of accidents on construction sites and thus reducing the occurrence rate of accidents on construction sites. The objectives of the study are to identify the key causal factors of accidents on construction sites and to investigate the frequency of occurrence of causes of accidents on construction sites.

Knowledge of the key indicators and dimensional causal factors of accidents will assist site managers and site supervisors to create awareness among construction workers on the significant causes of accidents on construction sites. Furthermore, the key indicators and dimensional causal factors of accidents will be of immense benefit to site workers, as it will help in easy identification and understanding of the causes of accidents on construction sites, thus preventing frequent occurrence rate of accidents.

\section{Literature Review}

\subsection{Accidents}

Accidents are events that lead to injury or ill health with consequences such as fatal, major injury, serious injury, minor injury and damage (HSE, 2004). This definition simply describes an accident in terms of its effect without reference to the cause. According to Eaves and Abercrombie (1946), there are two fundamental philosophies to the definition of accidents. While one philosophy defined accidents as 'the hand of fate reaching out to govern the course of human events', the other philosophy defined accidents as an event in which 'human beings are self-determining agents who can guide their destinies and thus avoid accidents'. Thus, the two philosophies described accidents from the perspective of fate and man. Accidents can simply be defined as an event caused by non-human or human factors that leads to injury or ill health.

Expanding on the consequences of accidents from the definition, fatal relates to work-related death while major injury includes any injury or illness that lead to unconsciousness and which require resuscitation or admittance to hospital for more than a day. Serious injury explains when the injured worker is absent from work for more than three consecutive days; minor injury describes when the injured worker is absent from work for less than three days. Damage is associated with damage to property, equipment, environment or production losses (HSE, 2004). Serious injuries and long-term disability are classified as a major accident while insignificant injuries and short-term disability are classified as minor (Yilzmaz and Celebi, 2015). Identifying the root causes of many injuries on construction sites is one of the ways of improving safety in the construction industry (AlTabtabal, 2002).

\subsection{Theories of Accidents}

Several theories exist for accident causation but this study adopts only two theories namely; accident multiple causation theory and accident root causes tracing model.

\section{Accident Multiple Causation Theory}

Accident multiple causation theory is based on the premise that there are many contributing factors, causes and sub causes of accidents (Peterson, 1971). The combination of all the factors causes accidents. Thus, the theory posits that not just one factor causes accidents but many factors combine randomly to cause accidents. Linking accident multiple causation theory to this study, the study posits that many factors cause accidents, these factors can be grouped causes (dimensional causes) and sub causes (indicators). Identifying these causes and sub causes will prevent accidents on construction sites.

Accident Root Causes Tracing Model (ARCTM)

Abdelhamid and Everret (2002) developed ARCTM and it is a model developed from the synthesis of previous models. The essence of the model was to provide an avenue in which the root causes of accidents can be easily identified compare to models with complex technical safety terms and definitions. The model shows the conditions that existed at the time of the accident and the antecedent human behaviour.

The main concept of ARCTM is that accident occur due to three root causes; (1) failing to identify an unsafe condition that existed before or after the start of an event (2) proceeding with an event after identifying the existing unsafe condition (3) deciding to act unsafely despite the initial conditions of the work environment 
(Abdelhamid and Everret, 2002). Since ARCTM provides an avenue for easy identification of the root causes of accidents as against the complex technical terms, this study proposes that grouping the causes of accidents into dimension and indicators will create an avenue for easy identification of the causes of accidents on construction sites as against complex terms.

\subsection{Causes of Accidents}

Reports abound on different causes of accidents in the construction industry, however, Abdullah and Wern (2010) note that the reports on accidents only describe the cases of accidents without mentioning the causal factors. Thus, it is pertinent to investigate the causal factors of accidents on construction sites. Although, various causal factors have been reported for construction site accidents, these factors have been reported in diverse ways. While some authors reported the causal factors individually without classifying them into dimensions, others categorised them into dimensions without considering the key indicators that make up the dimension. However, Williams et al. (2018) state that there is a dearth of research in the categorisation of accident causal factors. Furthermore, identifying and understanding these factors will extenuate construction accidents.

Choudhry and Fang (2008) opined accident causal factors among others include unsafe behaviour because of lack of safety awareness, inadequate supervision, inadequate planning, inadequate training, employee error and accident beyond one's control. These factors are majorly due to human error and were not categorised into groups. Causes of accidents according to Bashir et al. (2011) are prior work methods, physical and mental inability of workers, poor communication and poor planning. Masood et al. (2014) identified the major causes of accidents as defective PPE and taking productivity as a priority over safety. Ahmed (2019) concluded that the top five causes of accidents are lack of workers' awareness on safety-related issue, lack of pprotective equipment, lack of design that eliminate safety hazards, unfit equipment and lack of knowledge and training on equipment respectively. Orji et al. (2016) investigated 15 causes of accidents on construction sites and concluded that the major causal factors of accidents are failure to use personal protective equipment, injuries from equipment, sub-standard construction material, ignoring safe procedures and unsafe/incorrect construction method. Ibrahim and Tasiu's (2018) causes of accidents on confined construction sites are material handling, difficulty in providing temporary facilities, congestion, ergonomic hazards, difficulty in managing waste and lack of adequate storage. These causal factors of accidents are individual factors and construction workers may find it difficult to easily understand and identify the factors because they are numerous.

In categorising the causal factors of accidents, Al-Tabtabai (2002) categorised the causes of accidents into three major factors namely; management-related factors, labour and behavioural related factors and job or project-related factors. Olatunji et al. (2007) identified the main causes of accidents as tool problems, psychological problems, health problems, workmanship and material factor, contingencies, corporate health and safety orientation of the organisation. Using content analysis,
Tutesigensi and Reynolds (2008) identified the primary causes of accidents on construction sites as casualty error, work method, poor quality kit, poor health, site set up, site conditions, plant operator error, plant failure and packing error. Williams et al. (2018) identified various causal factors of accidents from literature and grouped them under five factors namely clientrelated, contractor-related, construction workers-related and construction site-related. An attempt has been made by these authors to group the causes of accidents due to numerous factors. However, the grouping of these factors did not include the key accident causal factors, there is, therefore, a need to consider these key factors for easy understanding of accident causal factors on construction sites.

\subsection{The Dimensionality of Accident Causal Factors on Construction Sites}

The dimensionality of accident causal factors has received little attention while the focus is on the individual causes of accidents. According to Al-Tabtabal (2002), preventing accidents begin with a clear understanding of the causal factors that play a key role in accident causation. There is, therefore, a need to classify these individual causes of accidents into dimensions for easy identification and understanding.

Kadri et al. (2014) examined the causes of accidents on construction sites; the factors were not grouped into major dimensions. The causes of accidents in their study include carelessness, negligence, scaffolds and so on. This study failed to classify accident causal factors into major dimensions. Promsorn et al. (2015) considered just one dimension of accident causal factors -non-human factors-. The factor was further classified into 21 variables and subdivided into three major factors namely, ergonomic design, supporting policy and environment. However, this study failed to consider the key causes of accidents under each dimension on construction sites. Similarly, Lingard et al. (2013) focused on plant-related fatalities in the Australian construction industry, the finding shows that people being run over by moving plant or struck by a moving object is the most common incident type. Lingard et al. study examined the causes of accidents from the perspective of accident types. There is, therefore, a need to differentiate the types of accidents from the causes of accident. Masood et al. (2014) identified the major reasons for accidents as defective equipment, site ergonomics, plant and equipment, the priority of productivity over safety. Likewise, this study failed to classify the causes of accidents into dimensions, also, the key indicators of each accident dimensions were not considered.

Although, some literature considered the causes of accidents from the dimensional perspective, however, the key dimensions were not investigated. For example, Abdul Hamid et al. (2008) grouped the causes of accidents into 6 dimensions namely, unsafe equipment, job site conditions, unique nature of industry, unsafe method, human element and management. This study failed to identify the key causes of accidents under each dimension. 


\section{Methodology}

To achieve the aim of the study, a positivist research paradigm, cross-sectional survey research design and quantitative research approach were employed. A cross-sectional survey research design was adopted because representative samples were taken from the population to generalize findings. Also, the research approach was quantitative because the key indicators and dimensions of accident causal factors were explained through the gathering of data in numerical form. The population of the study comprises site managers, site supervisors, safety officers, project managers working on various construction sites in Lagos state. Data was collected from the respondents through a purposive sampling technique using a structured questionnaire. This is because there are no lists of the population, therefore respondents working directly on site and who have one time or the other witness or experience accidents on construction sites were selected as respondents for this study. Three hundred questionnaires were thus purposely distributed to the respondents and 200 questionnaires were retrieved and valid for analysis representing a $67 \%$ response rate.

To measure the causes of accidents on construction sites, 64 observable variables were adapted from previous literature (Abdelhamid and Everett, 2000; Promsorn et al., 2015; González et al., 2016). Respondents were required to state the frequency of occurrence of the causes of accidents on construction sites using a five-point Likert scale, where $1=$ very low, $2=$ low, $3=$ moderately high, $4=$ high and $5=$ very high. For example, the frequency of occurrence of an accident due to nonuse of PPE is .... The 64 observable causal factors of accidents were thus analysed with the use of exploratory factor analysis.

\section{Result and Discussion}

A total of 200 respondents participated in the survey. Table 1 shows the demographic details of the respondents.

Table 1 Characteristics of Respondents

Respondents' Profile

Professional background

Architect

Freq.

$\%$

Builder

24

12

Civil engineer

123

61.5

Quantity surveyor

25

12.5

Mechanical engineer

11

5.5

Electrical engineer

8

9

4

Total

200

4.5

Professional qualification

Nigerian Institute of Architecture 24

(NIA)

Nigerian Institute of Building (NIOB) 116

Nigerian

Institute

of Quantity 22
Surveying (NIQS)

\begin{tabular}{lll} 
Nigeria Society of Engineers (NSE) & 34 & 17 \\
Others & 4 & 2 \\
Total & $\mathbf{2 0 0}$ & $\mathbf{1 0 0}$ \\
Position in the Company & & \\
Site Manager & 64 & 34 \\
Safety manager & 40 & 20 \\
Site Supervisor & 24 & 44.4 \\
Project manager & 37 & 18.5 \\
Total & $\mathbf{2 0 0}$ & $\mathbf{1 0 0}$ \\
Years of site experience & & \\
$<5$ years & 65 & 32.5 \\
5-10 years & 89 & 44.5 \\
11-15 years & 38 & 19 \\
16-20 years & 7 & 1 \\
$>$ 20 years & 1 & 5 \\
Total & 200 & 100 \\
Categories of organization & & \\
Indigenous & 187 & 93.5 \\
Multinational & 13 & 6.5 \\
Total & $\mathbf{2 0 0}$ & $\mathbf{1 0 0}$ \\
\hline
\end{tabular}

Freq. = Frequency

Table 1 shows that $61.5 \%$ of the respondents are builders by profession, while $12.5 \%$ are civil engineers. Thus, responses can be said to be from professionals in the construction industry, which implies that the information given is reliable. A larger percentage (44.4\%) of the respondents are professionals working as site supervisors on construction sites, $34 \%$ are site managers while $20 \%$ are safety officers. This is an indication that the credibility of the responses is high since the respondents directly work on site. In terms of experience, $44.5 \%$ have 5-10 years of working experience while $32.5 \%$ have working experience below 5 years. This shows that the respondents can give reliable information on the frequency of occurrence of causal factors of accidents on construction sites since they have appreciable years of working experience. $93.5 \%$ of the respondents work in indigenous construction firms while $6.5 \%$ work in multinational construction firms. This is because the Nigerian construction industry is characterised by a large number of indigenous construction firms and a low number of multinational construction firms.

\subsection{Key Dimensional Causes of Accidents on Construction Sites}

The sixty-four causal accident factors variables were factor analysis using maximum likelihood with proximate rotation to arrive at the key causal factors of accidents on construction sitess. The analysis in Table 2 yielded five factors explaining $68.54 \%$ of the variance for the entire set of variables with 22 observable variables. The factors were then grouped under five latent 
variables of personal/work factors, design factors, behavioural factors, proximate factors and attitudinal factors. Factor 1, labeled as personal/work factors consists of 10 variables and it explains $19.41 \%$ of the variance. The second factor 'design factors' consists of 5 variables and it explain $25.80 \%$ of the variance while the third factor consisting of three factors was labeled as behavioural factors and it explains $8.78 \%$ of the variance. The fourth factor 'proximate' explains $10.47 \%$ of the variance with two variables while the last factor labeled as 'attitudinal' factor consists of two variables and explains $3.86 \%$ of the variance. To test the factorability of the variables, the Kaiser-Meyer-Olkin (KMO) test of sampling adequacy was used which gave a value of 0.88 . This is within the acceptance range of value according to Field (2009). The Cronbach Alphas for the five factors are 0.938, $0.903,0.837,0.822$ and 0.734 which are above the minimum acceptable value of 0.7 (Field, 2009). Table 2 presents the dimensions of key causal factors of accidents on construction sites.

Table 2 Key Dimensional Causes of Accident on Construction Site

\begin{tabular}{|c|c|c|c|c|c|c|}
\hline $\mathbf{S} / \mathbf{N}$ & Causal Factors of Accident & $\begin{array}{l}\text { Personal/ } \\
\text { Work }\end{array}$ & Design & Behavioural & Proximate & Attitudinal \\
\hline 1 & Lack of judgment & 0.623 & & & & \\
\hline 2 & Lack of experience & 0.758 & & & & \\
\hline 3 & $\begin{array}{l}\text { Insufficient instruction } \quad \text { and/or } \\
\text { orientation }\end{array}$ & 0.97 & & & & \\
\hline 4 & Insufficient evaluation of needs and risks & 0.513 & & & & \\
\hline 5 & $\begin{array}{l}\text { Insufficient definition of policies, } \\
\text { procedures, practices or action steps }\end{array}$ & 0.877 & & & & \\
\hline 6 & Inadequate standards or specifications & 0.565 & & & & \\
\hline 7 & Inadequate storage of materials & 0.76 & & & & \\
\hline 8 & $\begin{array}{l}\text { Inadequate control and inspection of } \\
\text { construction sites }\end{array}$ & 0.801 & & & & \\
\hline 9 & Inadequate handling of materials & 0.764 & & & & \\
\hline 10 & Inadequate maintenance of standards & 0.569 & & & & \\
\hline 11 & Vibrations from machines & & 0.731 & & & \\
\hline 12 & Equipment design & & 0.945 & & & \\
\hline 13 & Design of PPE & & 0.691 & & & \\
\hline 14 & Innovative technology & & 0.788 & & & \\
\hline 15 & Standard performance causes discontent & & 0.676 & & & \\
\hline 16 & Carrying overload & & & 0.811 & & \\
\hline 17 & Wrong posture of carrying loads & & & 0.705 & & \\
\hline 18 & Nonuse of PPE & & & 0.865 & & \\
\hline 19 & Difficulty in traffic & & & & 0.524 & \\
\hline 20 & Working in confined space & & & & 0.993 & \\
\hline 21 & Disobedience to work discipline & & & & & 0.569 \\
\hline \multirow[t]{2}{*}{22} & Uncertainty or hazard & & & & & 0.943 \\
\hline & Cronbach Alpha & 0.938 & 0.903 & 0.837 & 0.822 & 0.734 \\
\hline
\end{tabular}

Extraction Method: Maximum Likelihood. Rotation Method: Promax with Kaiser Normalization. a Rotation converged in 7 iterations. KMO=0.888, Barlett's Test $=3341.405$, Df $=.231$, Sig $=000$

The first dimensional causal factor of accidents was labeled 'work/personal factors' because the key indicators reflect accident causes due to individual personality or activity directed at achieving tasks. For example, lack of judgment, lack of experience and inadequate control and inspection of construction sites. The second dimensional causal factor of accidents was labeled 'Design factor' because the key indicators reflect causes that originate from the design of equipment and technology. For example, vibrations from machine or equipment design. The third dimensional accident causal factor of accidents was termed 'behavioural factors'. This is because behavioural factors reflect indicators resulting from unsafe behaviour at work, for example, non-use of PPE. The fourth dimensional accident causal factor was labeled 'proximate factors' because the indicators reflect the closeness of space or lack of space, for example working in confined space. The last dimensional accident causal factor was termed 'attitudinal factor' because the indicators reflect the state of individual belief, feeling, values and dispositions, for example, disobedience to work discipline.

\subsection{Causes of Accidents on Construction Sites}

The prevalent causes of accidents on construction sites were investigated using the key dimensional causes of accidents. To achieve this, the mean score of each key dimensional causes of accident measured as a latent variable were calculated. The mean values were interpreted using the following scales, 1.00-1.49 for very low; 1.50-2.49 for low; 2.50-3.49 for moderately high; 3.504.49 for high and 4.50-5.00 for very high. Table 3 shows the causes of accidents on construction sites. 
Table 3 Causes of Accident on Construction Sites

\begin{tabular}{|c|c|c|c|c|c|c|c|}
\hline Accident Causal Factors & 1 & 2 & 3 & 4 & 5 & Total & Mean \\
\hline Work/Personal Factors & 3.6 & 9.6 & 36.8 & 103.4 & 46.6 & 200 & 3.90 \\
\hline Lack of judgment & 3 & 11 & 65 & 84 & 37 & 200 & 3.71 \\
\hline Lack of experience & 3 & 8 & 23 & 103 & 63 & 200 & 4.08 \\
\hline Insufficient instruction and/or orientation & 3 & 14 & 40 & 97 & 46 & 200 & 3.85 \\
\hline Insufficient evaluation of needs and risks & 2 & 11 & 30 & 111 & 46 & 200 & 3.94 \\
\hline $\begin{array}{l}\text { Insufficient definition of policies, procedures, } \\
\text { practices or action steps }\end{array}$ & 3 & 7 & 38 & 106 & 46 & 200 & 3.93 \\
\hline Inadequate standards or specifications & 3 & 17 & 33 & 108 & 39 & 200 & 3.82 \\
\hline Inadequate storage of materials & 8 & 7 & 45 & 99 & 41 & 200 & 3.79 \\
\hline Inadequate control and inspection of construction sites & 3 & 8 & 27 & 110 & 52 & 200 & 4.00 \\
\hline Inadequate handling of materials & 5 & 10 & 35 & 104 & 46 & 200 & 3.88 \\
\hline Inadequate maintenance of standards & 3 & 3 & 32 & 112 & 50 & 200 & 4.02 \\
\hline Design Factors & 7.2 & 20.2 & 47 & 93.4 & 32.2 & 200 & 3.62 \\
\hline Vibrations from machines & 7 & 20 & 49 & 92 & 32 & 200 & 3.61 \\
\hline Equipment design & 7 & 26 & 47 & 97 & 23 & 200 & 3.52 \\
\hline Design of PPE & 4 & 18 & 43 & 104 & 31 & 200 & 3.7 \\
\hline Innovative technology & 14 & 23 & 52 & 70 & 41 & 200 & 3.51 \\
\hline Standard performance causes discontent & 4 & 14 & 44 & 104 & 34 & 200 & 3.75 \\
\hline Behavioural Factors & 1 & 8.33 & 22 & 93.33 & 75.33 & 200 & 4.17 \\
\hline Carrying overload & 3 & 8 & 22 & 94 & 73 & 200 & 4.13 \\
\hline Wrong posture of carrying loads & 0 & 9 & 26 & 93 & 72 & 200 & 4.14 \\
\hline Nonuse of PPE & 0 & 8 & 18 & 93 & 81 & 200 & 4.24 \\
\hline Proximate Factors & 7 & 12 & 50 & 81.5 & 49.5 & 200 & 3.78 \\
\hline Difficulty in traffic & 8 & 14 & 56 & 73 & 49 & 200 & 3.71 \\
\hline Working in confined space & 6 & 10 & 44 & 90 & 50 & 200 & 3.84 \\
\hline Attitudinal Factors & 16 & 12 & 27 & 97 & 48 & 200 & 3.75 \\
\hline Disobedience to work discipline & 14 & 9 & 12 & 106 & 59 & 200 & 3.94 \\
\hline Uncertainty or hazard & 18 & 15 & 42 & 88 & 37 & 200 & 3.56 \\
\hline
\end{tabular}

Table 4 Key Dimensions Accident Causal Factors On Construction Site

\begin{tabular}{lllllllll}
\hline Accident Causal Factors & $\mathbf{1}$ & $\mathbf{2}$ & $\mathbf{3}$ & $\mathbf{4}$ & $\mathbf{5}$ & Total & Mean & Rmk \\
\hline Behavioural Factors & 1 & 8.33 & 22 & 93.33 & 75.33 & 200 & 4.17 & High \\
Work/Personal Factors & 3.6 & 9.6 & 36.8 & 103.4 & 46.6 & 200 & 3.90 & High \\
Proximate Factors & 7 & 12 & 50 & 81.5 & 49.5 & 200 & 3.78 & High \\
Attitudinal Factors & 16 & 12 & 27 & 97 & 48 & 200 & 3.75 & High \\
Design Factors & 7.2 & 20.2 & 47 & 93.4 & 32.2 & 200 & 3.62 & High \\
\hline
\end{tabular}


The result in Table 4 shows that the frequency of occurrence of all the dimensional causes of accident namely behavioural, work/personal, proximate, attitudinal and design factors are high.

The implication is that the rates at which accidents occur on site due to all the dimensions are eminent. Furthermore, the most prevalent cause of accidents on construction sites is behavioural factors with a mean value of 4.17. This implies that accidents occur mostly on site due to the conduct of site workers. Particularly, Table 3 shows that the non-use of PPE accounts for the highest behavioural factors. Wrong posture of carrying a load and carrying overload are conducts from individual workers, which originate from their behaviour.

The least cause of accidents is design factors with a mean value of 3.62. This shows that the vibration from machines, equipment design, design of PPE, innovative technology and standard performance are the least causes of accidents on construction sites.

\subsection{Discussion of Findings}

From the gap established in this study, the key indicators and dimensional causal factors of accident must be investigated to identify the genesis of accidents on construction sites for proper training of site workers. Thus, the first objective was to identify the significant accident causal factors indicators, thereafter group the indicators into dimensions. Table 1 shows the key dimensional causes of accidents with their indicators on construction sites. Five key dimensional causes of accident on construction sites namely behavioural factors, work/personal factors, proximate factors, attitudinal factors, design factors were identified from the factor analysis conducted.

\section{Behavioural factors}

Findings from the study show that one of the key dimensional causes of accidents on construction sites is behavioural factors. This implies that the genesis of accidents on construction sites originates from the conduct of the individual workers on site. Such conduct includes carrying overload, wrong posture of carrying load and non-use of PPE. Table 3 shows that the non-use of PPE is the most prevalent cause of behavioural causes of accidents. Doddo and Al-Samarraie (2019) emphasised that behavioural conduct such as non-use of protective equipment is one of the factors of unsafe behaviour. Furthermore, Ali et al. (2010) conclude that the non-use of PPE is one of the major causes of accidents on construction sites. It then becomes imperative to identify this unsafe conduct and identify ways of ensuring good conduct on site. Mahalingam and Levitt's (2007) findings show that education and training for changing the mindset and behaviour of workers on safety on construction sites were not effective. However, the strategy of coercive enforcement through the payment of fines was effective. Hon et al. (2014) suggested using the dual approach in changing the mindset of workers to safety conduct on site. Thus, knowledge of behavioural factors as key dimensional causal factors of accidents will assist both the health and safety personnel and construction workers on site.
Work/personal Factors

Another key dimensional causal factor of accidents identified on construction sites in Table 4 is work/personal factors. It explains the key indicators of causes of accidents due to individual personality or activity directed at achieving given tasks. This finding is in line with Al-Tabtabai (2002) in which workers and job factors were identified as two major causes of accidents on construction sites. The workers' factors refer to personal factors while job factors refer to work factors. Although Zhang et al. (2019) found out that poor management was a critical causal factor compare to individual factors, the fact remains that both are causal factors of accidents on construction sites. This suggests that work/personal factors are important causes of accidents on construction sites.

Findings from the result in Table 3 show that lack of experience and inadequate maintenance of standards following workflows, updating, control of the use of standards/processes/rules were the major indicators of work/personal causal factors of accidents. Among the key factors is insufficient instruction or inadequate orientation to workers. This substantiate the findings of Choudhry and Fang (2008) and Ahmed (2019) in which inadequate training and lack of knowledge and training on equipment were found to be major causal factors of accidents on construction sites.

\section{Proximate Factors}

Proximate factors, which indicate accidents due to closeness of space, are among the dimensional causes of accidents. Table 3 shows that there are two major indicators of proximate causal factor of accidents; difficulty in traffic and working in confined space. According to McAleenan and McAleenan (1999), many severe accidents happen on site due to confined space. This finding confirms that of McAleenan and McAleenan (1999), Ibrahim and Tasiu (2018) and Naghavi et al. (2019) in that confined space, which is a proximate factor, was said to be a causal factor of accidents. It is necessary to consider the issue of confined space on site as it has different implications. Such implications include among others; difficulty in providing temporary facilities, congestion and ergonomic hazards. The consequence of these implications is the occurrence of accident. (Ibrahim and Tasiu, 2018).

\section{Attitudinal Factors}

The fourth dimensional cause of accidents in Table 4 is attitudinal factors. Attitudinal factors are factors that reflect the state of individual beliefs, feeling, values and dispositions. This suggests that individual dispositions toward accidents play a significant role in the causes of accidents. This finding supports that of Tutesigensi and Reynolds (2008) in which individual attitudes towards health and safety were found as a major cause of accidents. For construction workers to have a change of attitude, they must have the ability and willingness to implement safe approaches to work. 
Design factors

The result in Table 4 shows that the least cause of accidents on construction sites is design factors. This suggests that the least causes of accidents on construction site are due to the design of equipment or innovative technology. The key indicators of design factors are presented in Table 3. The implication is that most sub causes of design dimensional causes of accidents are equipment design, innovative technology, vibration from machine and design of PPE. These factors are beyond the capacity of site workers and are due to the fault of the design and technology of equipment. The finding supports that of Promosorn et al. (2015) in which design of equipment, innovative technology, design of PPE, vibration from machine were found to be indicators of ergonomic design cause of accidents.

\section{Conclusion and Recommendation}

Identifying the key indicators of accident causal factors is necessary for the prevention of accidents on construction sites. Thus, the study sought to identify the key indicators and dimensions of the causes of accidents on construction sites. Five key dimensional causes of accidents were discovered with 22 indicators. The study thus concludes that behavioural factors, work and personal factors, proximate factors, attitudinal factors and design factors are the key dimensional causes of accidents on construction sites. Furthermore, the study concludes that the major indicators for each of the dimensional factors are non-use of PPE, lack of experience, working in confined spaces, disobedience to work discipline and innovative technology.

The key accidents causal factors indicators will serve the purpose of self-evaluation and firm evaluation for construction site workers and firms. This will create consciousness on the part of the site workers and management of the firm on the importance of avoiding such acts that can cause accidents on construction sites. Furthermore, site managers can adopt the key indicators and dimensional causes of accidents as a training guide to construction site workers. The indicators can be placed on a signboard on construction sites for easy identification and understanding. It will also serve as a means of awareness and regular self-check which will reduce the frequency of occurrence of accidents on construction sites.

The focus of the study was on the key indicators and dimensional causes of accidents on construction sites. An exploratory factor analysis was employ in determining the key indicators; future study should consider the use of confirmatory factor analysis to confirm the indicators. Furthermore, the key safety accidents prevention measures were not considered in this study, future study should consider the safety prevention measures needed for the key indicators of accidents on construction sites.

\section{Acknowledgements}

The authors acknowledge all the construction personnel that participated in this research.

\section{References}

Abdelhamid, T.S., \& Everett, J.G. (2000). Identifying root causes of construction accidents. Journal of Construction Engineering and Management, 126: 52-60.

Abdul Hamid, A. R. A., Abd Majid, M. Z. \& Singh, B. (2008). Causes of accidents at construction sites. Malaysian Journal of Civil Engineering, 20(2): 242-259.

Abdullah, D.N.M.A. \& Wern, G.C.M. (2011). An analysis of accidents statistics in Malaysian construction sector. In $10^{\text {th }}$ International Conference on E-business, Management and Economics, 3: 1-4. Hong Kong: IACSIT Press.

Adekunle, A., Umanah, I.I., Adewale, A.K. \& Egege, C.C. (2018). Analytical study of casualties in the construction industry in Nigeria with a view to provide remedial measures: Case study of Lagos State. International Journal of Engineering Research and Advanced Technology, 4(8): 6-14 DOI: http: / / doi.org/10.31695/IJERAT.2018.3293

Ahmed, S. (2019). Causes and effects of accident at construction site: A study for the construction industry in Bangladesh. International Journal of Sustainable Construction Engineering and Technology, 10(2): 18-40.

Ali, A. S., Kamaruzzaman, S. N. \& Sing, G. C. (2010). A Study on causes of accident and prevention in Malaysian construction industry. Journal of Design+ Built, 3(1), 95-104.

Al-Tabtabai, H.M. (2002). Analyzing construction site accidents in Kuwait. Kuwait Journal of Science and Engineering, 29(2): 213-238.

Asanka, W.A. \& Ranasinghe, M. (2015). Study on the impact of accidents on construction projects. In 6th International Conference on Structural Engineering and Construction Management, $11^{\text {th }}-13^{\text {th }}$ December 2015, Kandy, Sri Lanka, 58-67.

Bashir, A.M., Suresh, S., Proverbs, D. \& Gameson, R. (2011). A critical, theoretical, review of the impacts of lean construction tools in reducing accidents on construction sites In: Egbu, C. \& Lou, E.C.W. (Eds.) Procs 27th Annual ARCOM Conference, 5-7 September 2011, Bristol, UK, Association of Researchers in Construction Management, 249-258.

Choudhry, R.M. \& Fang, D. (2008). Why operatives engage in unsafe work behavior: Investigating factors on construction sites. Safety Science, 46(4): 566-584. DOI:10.1016/j.ssci.2007.06.027

Dodoo, J.E. \& Al-Samarraie, H. (2019). Factors leading to unsafe behavior in the twenty first century workplace: A review. Management Review Quarterly, 69(4):391-414. DOI: https: / / doi.org/10.1007/s1 1301-019-00157-6

Eaves, R.W. \& Abercrombie, S.A. (1946). Concepts of accidents. The Journal of Educational Sociology, 20(2): 85-90.

Eze, C. Auyba, P, \& Shittu, A.A. (n.d), Assessment of accident hazard in Nigerian building industry. Retrieved, 27 May, 2020 from staff.futminna.edu.ng , $A R C$, content, journal , 5.pdf

Field, A. (2009), Discovering Statistics Using SPSS, SAGE Publications, London. 
González, A., Bonilla, J., Reyes, C. \& Chavarro, A. (2016). Analysis of the causes and consequences of accidents occurring in two constructions projects. Revista Ingeniería de Construcción, 31(1): 5-16.

Ha, T. J. \& Nemeth, Z.A. (1995). Detailed study of accident experience in construction and maintenance zones. Transportation Research Record: 3845.

Health and Safety Executive (HSE), (2004). Investigating accidents and incidents: A workbook for employers, unions, safety representatives and safety professionals. Retrieved, 27 May 2020 from www.hse.gov.uk > pUbns > hsg245

Hon K.H., Jimmie, C.H. \& Chan A.P.C., (2014). Safety climate and injury occurrence of repair, maintenance, minor alteration and addition works Facilities, 32(5/6):188-207 DOI: http://dx.doi.org/10.1108/F09-2011-0066

Ibrahim, A.H. \& Tasiu, M., (2018). Health and safety issues on confined building sites in nigeria. In Proceedings of the Joint CIB W099 and TG59 Conference Coping with the Complexity of Safety, Health, and Wellbeing in Construction Salvador, Brazil, 1-3 August, 405-413.

Kadiri, Z. O., Nden, T., Avre, G. K., Oladipo, T. O., Edom, A., Samuel, P. O. \& Ananso, G. N., (2014). Causes and effects of accidents on construction sites (A case study of some selected construction firms in Abuja FCT Nigeria). Journal of Mechanical and Civil Engineering, 11(5): 6672.

Lingard, H., Cooke, T., \& Gharaie, E. (2013). The how and why of plant-related fatalities in the Australian construction industry. Engineering, Construction and Architectural Management, 20(4): 365-380. DOI: https://doi.org/10.1108/ECAM-09-2011-0085.

Mahalingam, A. \& Levitt, R.E., (2007). Safety issues on global projects. Journal of Construction Engineering and Management, 133(7):506-516. DOI: 10.1061/_ASCE_07339364_2007_133:7_506_

Masood, R., Mujtaba, B., Khan, M.A., Mubin, S., Shafique, F. \& Zahoor, H. (2014). Investigation for safety performance indicators on construction projects. Science International, 26(3): 1403-1408.

McAleenan, C. \& McAleenan, P. (1999). Confined Spaces WorkingTowards Zero Fatalities. Retrieved May 162020 from expertease@confinedspaces.com
Naghavi, Z., Mortazavi, S. B. \& Hajizadeh, E. (2019). Exploring the contributory factors of confined space accidents using accident investigation reports and semistructured interviews. Safety and Health at Work, 10(3): 305-313. https://doi.org/10.1016/j.shaw.2019.06.007

Olatunji, O.A., Aje, O.I. \& Odugboye, F. (2007). Evaluating health and safety performance of Nigerian construction site. In CIB World Building Congress, Rotterdam, Netherlands May, 1176-1190.

Orji, S. E., Enebe, E. C. \& Onoh, F. E. (2016). Accidents in building construction sites in Nigeria: A case of Enugu State. International Journal of Innovative Research and Development, 5(4): 244-248.

Perttula, P., Merjama, J., Kiurula, M. \& Laitinen, H. (2003). Accidents in materials handling at construction sites. Construction Management and Economics, 21(7): 729-736. DOI: 10.1080/0144619032000087294

Petersen, D. (1971). Techniques of safety management. McGraw-Hill, New York.

Promsorn, P., Soponsakulrat, P., Adulyanukosol, C., Kaiyarit, P. \& Chinda, T. (2015). Identifying root causes of construction accidents: Non-Human error factors. International Journal of Computing, Communication and Instrumentation Engineering, 2(1):1-5. DOI: http://dx.doi.org/10.15242/IJCCIE.IAE0715004

Tutesigensi, A. \& Reynolds, J.R. (2008). Causes of accidents on construction sites: The case of a large construction contractor in Great Britain. In: Hinze, J., Bohner, S. and Lew, J., (eds.) Proceedings of CIB W99 14th Rinker International Conference. Evolution of and Directions in Construction Safety and Health. CIB W99 14th Rinker International Conference, $9^{\text {th }}-11^{\text {th }}$ March, 2008, Gainesville, Florida, USA., 433-444.

Umar, T \& Egbu, C. (2018). Causes of construction accidents in Oman. Middle East Journal of Management, 5(1): 21-33.

Williams, O.S., Hamid, R.A., \& Misnan, M.S. (2018). Accident causal factors on the building construction sites: A review. International Journal of Built Environment and Sustainability, 5(1): 78-92. DOI:10.11113/ijbes.v5.n1.248 